\title{
MITRAL STENOSIS IN LATER LIFE
}

4
BY

\author{
HAROLD COOKSON
}

Received October 28, 1948
Rheumatic heart disease with mitral stenosis has been regarded as a disease that produces symptoms in adolescence or early adult life, and death before the age of forty in the majority. It is admitted that occasionally the first symptoms will appear at the time of the menopause and that if the lesion is accompanied by hypertension, life may be prolonged beyond this period (Levine, 1945). The few clinical observations that have been made on the subject, put the incidence of mitral stenosis beyond the age 50, at from 6 to 10 per cent (Coombs, 1924; Brenner, 1934; Hedley, 1940) (see Table I). Levine and

TABLE I

Mitral Stenosis (or Rheumatic Heart Disease) (Proportion of cases over 50 years of age)

\begin{tabular}{|c|c|}
\hline Clinical cases Author & Necropsy cases Author \\
\hline $\begin{array}{l}\text { 1. Coombs (1924) } 6 \% \\
\text { 2. Brenner (1934) } 10 \% \\
\text { 3. Hedley (1940) } 7 \%\end{array}$ & $\begin{array}{l}\text { 1. Coombs (1924) } 9 \% \\
\text { 2. Cabot (1926) } \\
\text { 3. Cookson (1930) } 12 \% \\
\text { (M.S. and A.F. over age } \\
\text { 48) } \\
\text { 4. Brenner (1934) } 20 \% \\
\text { 5. Hedley (1940) } 11 \% \\
\text { 6. White and Bland }(1941) \\
\text { (5 cases, aged 73-85) } \\
\text { 7. Gelfman (1943) } 33 \% \\
\text { 8. Zeman (1945) } \\
\text { (10 patients aged } 60-74 \\
\text { with M.S. and subacute } \\
\text { bacterial endocarditis) } \\
\text { 9. Karsner and Koletsky } \\
\text { (1947) } \\
\text { (48 with M.S. and aortic } \\
\text { calcification in elderly } \\
\text { patients) }\end{array}$ \\
\hline
\end{tabular}

Kauver (1941-42) were able to collect from the records of a hospital and a private practice over about a quarter of a century, 28 patients over 50 years of age with mitral stenosis and angina pectoris. But-more information is available from post-mortem studies than from clinical reports on the question of mitral stenosis in the elderly. These reports give the percentage of patients dying with mitral stenosis at age 50 or more as from 9 to 33 per cent, figures that are so much higher than those for the clinical incidence as to suggest that the diagnosis is often missed during life (Coombs, 1924; Cabot, 1926; Cookson, 1930; Brenner, 1934; Hedley, 1940; White and Bland, 1941; Gelfman, 1943; Zeman, 1945; Karsner and Koletsky, 1947) (Table I).

The present investigation concerns 37 patients with mitral stenosis and one with mitral incompetence, ranging in age from 51 to 77 years. There were only 9 men, giving a sex ratio of more than 3 females to 1 male, which is higher than that for all cases of mitral stenosis. (Table II.) The

\section{TABLE II}

Thirty-eight Patients with Mitral Disease OVER FIFTY

\begin{tabular}{|c|c|}
\hline Age & Number \\
\hline $\begin{array}{l}51-60 \\
61-70 \\
71-77\end{array}$ & $\begin{array}{rllll}26 & (18 & \text { F. } & 8 & \text { M. }) \\
8 & (7 & \text { F. } & 1 & \text { M. }) \\
4 & (4 & \text { F. } & 0 & \text { M. })\end{array}$ \\
\hline
\end{tabular}

predominance of women increased in each successive decade so that all patients over 70 were women. A greater number was seen in private than in hospital practice which is the reverse of the distribution for younger age groups. There was a clear history of rheumatic fever or chorea in 15 , and in a further 8 , a valve lesion or heart disease had been diagnosed in childhood or early adult life. In 5, the first known attack of rheumatic fever occurred at the age of 34 or later, and recurrent attacks after the age of 30 were mentioned in 2 others.

All had lived actively and, though some admitted that they had never been capable of strenuous exertion because of shortness of breath, the general capacity for work was at least average. Of 23 
women who were married, 18 had had children, in one case, five.

\section{INITIAL SYMPTOMS}

When first seen, 32 of the 38 cases had established auricular fibrillation; 2 came under observation with paroxysmal tachycardia, 1 with paroxysmal fibrillation, and only 3 had normal rhythm. In one of these last, fibrillation set in after a few weeks. In 8 cases a sudden onset of symptoms, mainly palpitation and dyspnœa, was known to coincide with the occurrence of fibrillation or was strongly suggested by the history. In 3 , the first symptoms were due to cerebral embolism, in one to pulmonary infarction and in one to ischæmia of the legs. Congestive failure was present in about one third of all cases when they were first seen, and this nearly always responded to appropriate treatment. In a further third, systemic congestion developed during the period of observation and treatment which was generally a matter of years. Failure under these conditions was resistant to treatment though some survived in a state of invalidism for months or years. Systemic congestion with normal rhythm was observed in one patient only. Two patients who died from the effects of left auricular thrombosis never showed signs of systemic congestion. They had auricular fibrillation and symptoms for six months and four years respectively.

\section{DiAgNosis}

The diagnosis of mitral stenosis in the patients in this series, was made on the presence of a rough, low-pitched diastolic murmur heard best at the apex beat or occasionally a short distance from it, as for example in the intercostal space above the apex. The murmur begins very soon after the second sound, is decrescendo, dying away as a rule before the first sound, though rarely reaching it. In this last event an impression of a crescendo presystolic murmur is possible even with auricular fibrillation. The diastolic murmur may be so rough as to be unmistakably that of mitral stenosis, but more often it is softer, yet not of the blowing quality characteristic of the aortic diastolic murmur. Nevertheless, when aortic incompetence was present, as it was in ten patients, mitral stenosis was not considered proved by a low pitched apical murmur, unless characteristic X-ray changes of mitral stenosis were present. The diastolic murmur of mitral stenosis in the elderly requires careful and sometimes lengthy auscultation for its detection, and it may be quite inaudible in any but the long diastoles. Mitral stenosis may of course exist when the only murmur is systolic. There were two cases of this type, in which the diagnosis was established post-mortem, but apart from these a mitral diastolic murmur had been heard in all, though not necessarily on every occasion the patient was examined. Subsidiary signs of mitral stenosis were usually present; in order of frequency these were a sharp first sound, a third heart sound, accentuated pulmonary second sound, and flushed or cyanotic appearance of the malar eminence.

\section{HyPERTENSION}

Levine (1945) remarked on the frequency of arterial hypertension in older patients with mitral stenosis, and indeed ascribed their longivity to this complication. It is not easy, however, to determine the frequency of hypertension in these cases as the blood pressure is difficult to estimate. This is, first, because of the almost invariable presence of auricular fibrillation and second because there is sometimes aortic incompetence, both of which conditions tend to give high readings for the systolic and lower readings for the diastolic pressure. In the present cases a minimum diastolic pressure of $100 \mathrm{~mm}$. or more was found in 19 (50 per cent). On this criterion of hypertension, it was present in one half of all patients. Taking a systolic pressure of $190 \mathrm{~mm}$. or more as a criterion of hypertension, it was present in 12 (31 per cent) of cases. With either of these standards the incidence of arterial hypertension must be regarded as high in mitral stenosis in the elderly.

Yet in spite of this high proportion with hypertension and the advanced average age of the subjects, characteristic anginal pain was experienced by one patient only. This was a woman of 71 with mitral stenosis, aortic incompetence, and auricular fibrillation. Her blood pressure was $160 / 100 \mathrm{~mm}$. She described typical retrosternal pain in walking up steep hills. She had never shown any signs of systemic congestion. In a further two patients, however, pain occurred which may be regarded as anginal. This was in 2 men who died of left auricular thrombosis and who complained shortly before death of pain in the lower chest and epigastrium.

\section{Radiological Appearances}

The accepted X-ray cardiac changes in mitral stenosis are an increase in the left middle arc so that the usual slight concavity in this region comes into line with the left lower contour and the shadow of the aortic knuckle, or there is a convexity in this region which may be single or double. The vascular pedicle is narrow and the aortic knob is small or non-existent. Displacement of the cesophagus 
backward and to the right reveals an enlargement of the left auricle. At first these changes are not accompanied by any alteration in the shape of the left lower contour or of the right contour, but as time passes these also become more or less prominent, and on the right border may be seen a double contour produced by the two auricles.

Radioscopy and radiography were carried out in all cases except five, and in three of these five, necropsy was done. A cardiac silhouette that could be regarded as within normal limits was seen only once. (Fig. 1A and 1B.) This was in a man aged 58 whose only known attack of rheumatic fever occurred when he was 45: auricular fibrillation was present but symptoms were very mild. Slight general cardiac enlargement with increase in the left middle arc was also unusual. An example is shown in Fig. 2 taken from a man of 53 who had normal blood pressure and whose heart at necropsy weighed 325 g., with moderate right ventricular hypertrophy, the left ventricle being normal. The onset of auricular fibrillation causes a rapid increase in the size of the heart even in the absence of systemic congestion. This is shown in Fig. 3 and 4 from a woman aged 51. The first of these radiographs was taken while normal rhythm was present and the second a few weeks later after auricular fibrillation had developed; it shows some increase in the right, left lower and left middle contours of the heart. Increase in the size of the left auricle sufficient to bring it to the right heart border was seen in five cases, although in the first oblique position they usually showed only moderate displacement of the cesophagus. Deviation of the cesophagus to the left and backward instead of to the right and backward was met with in two patients. (Fig. 5, 6, 7, and 8.) This is well seen on screening after barium swallow in the second oblique position or in the face position, but in the first position the course of the œsophagus may appear almost normal. The narrow vascular pedicle and inconspicuous aortic knob characteristic of the X-ray picture in young subjects with mitral stenosis was never seen. On the contrary the knob was always visible and often prominent, though this prominence tends to be minimized by the increased middle arc below it.

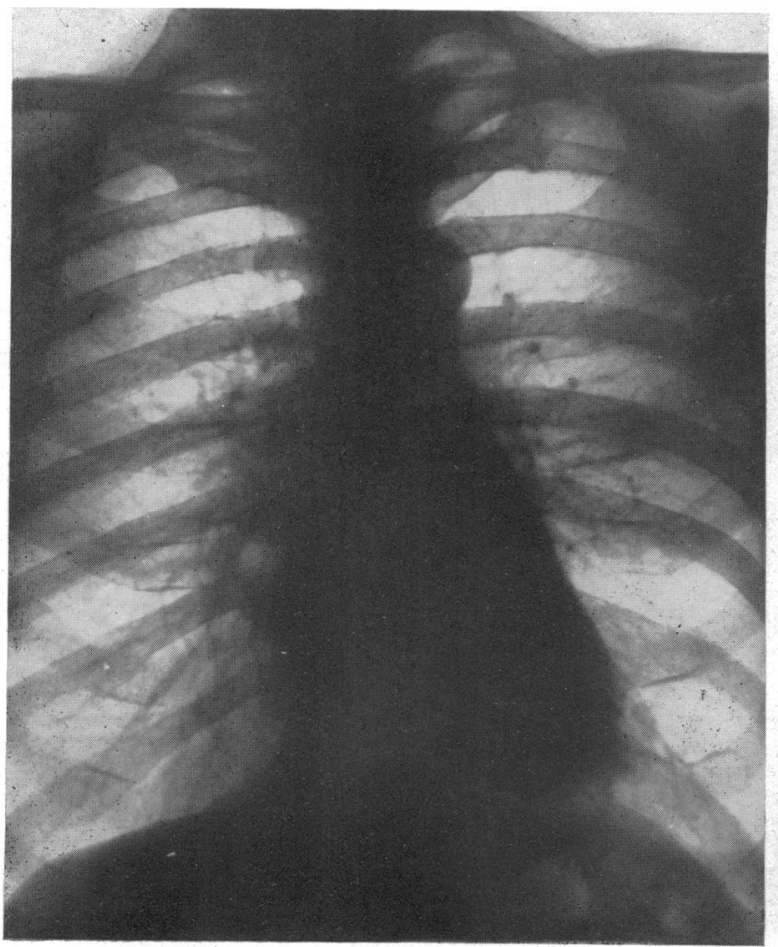

A

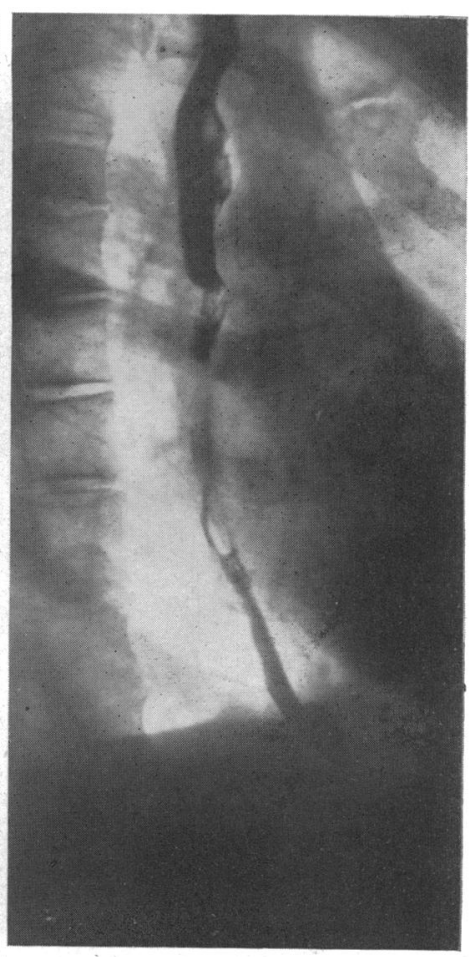

B

FIG. 1.-Man, aged 58; an Army officer on active service until age 56; only known attack of rheumatic fever at age 45; mitral stenosis, auricular fibrillation. (A) Postero-anterior radiograph shows heart of normal size and shape, or possibly minimal increase in left middle arc. 
When the left lower contour is also well out, the result is a contour which bears no resemblance to the typical silhouette of mitral stenosis.

A well marked aortic impression on the œsophagus and the opacities of aortic calcification are also common features of the X-ray picture of mitral stenosis in the elderly. Fig. 9 and 10 represent the characteristic features of mitral stenosis combined with great cardiac enlargement in three women aged 71,74 , and 77 respectively (see pp. 162-163).

\section{Cause of Death}

Sixteen of the 38 patients died after an average duration of symptoms of $4 \frac{1}{2}$ years, the average age at death being 62 years. Twelve died with systemic congestion complicated in two by cerebral vascular lesions, acute rheumatism in one and pulmonary infarction in one. Two died from acute pulmonary congestion. In four of the sixteen cases necropsy was done. Two of these showed thrombosis of the left auricle, the thrombus extending on to the mitral valve and further obstructing it. The first, a man aged 60, had some abdominal and leg pains, then developed a sudden painful paraplegia, with pain also in the chest and left arm and delirium. There was a complete absence of arterial pulsation in the legs which quickly became gangrenous. Death occurred on the 19th day. Necropsy showed an extreme mitral stenosis, the orifice just admitting the tip of the little finger. A large soft vegetation measuring $3 \mathrm{~cm} . \times 2 \mathrm{~cm}$. was situated on the left auricular wall extending on to the aortic cusp of the mitral valve and encroaching on its opening (Fig. 11). Just above the bifurcation of the aorta there was a small dissecting aneurysm of its wall with leakage of a little blood into the retro-peritoneal tissues (Fig. 12, page 164).

The second, a man of 53, had lower chest or epigastric pain with symptoms of cerebral anoxæmia a few hours before death. Necropsy again showed extreme mitral stenosis with a loose fresh-looking

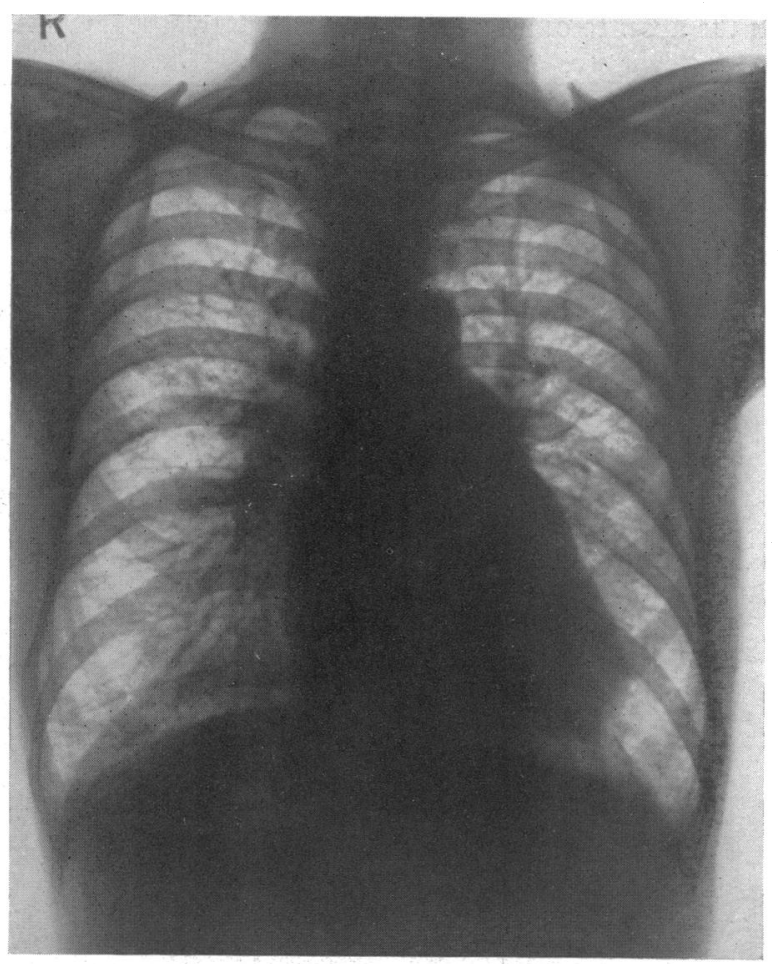

Fig. 2.-Man, aged 53. Mitral stenosis and auricular fibrillation; postero-anterior radiograph shows prominence of pulmonary artery and of conus separately, but no prominence of other cardiac contours; aortic knob prominent. Necropsy: severely stenosed calcified mitral valve with fresh thrombus on its auricular aspect; left ventricle not enlarged; heart weight, $325 \mathrm{~g}$. 
clot blocking the orifice. Rough calcified plaques almost encircled the base of the valve. Neither of these two patients with severe mitral obstruction had shown signs of systemic congestion. Their chest pain near the end may have been cardiac in

\section{TABLE III}

\section{Cause of Death in Sixteen Patients}

(Average age at death 62 years)

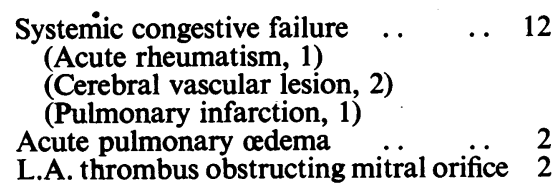

origin and due to auricular thrombosis as suggested by Evans and Benson (1948). In a third case, a woman of 62 , necropsy showed pure mitral incompetence. The clinical diagnosis had been hypertension and congestive failure, though there was a history of rheumatic fever in childhood, and valve disease had been diagnosed at age 7 . The layers of the pericardium were densely adherent

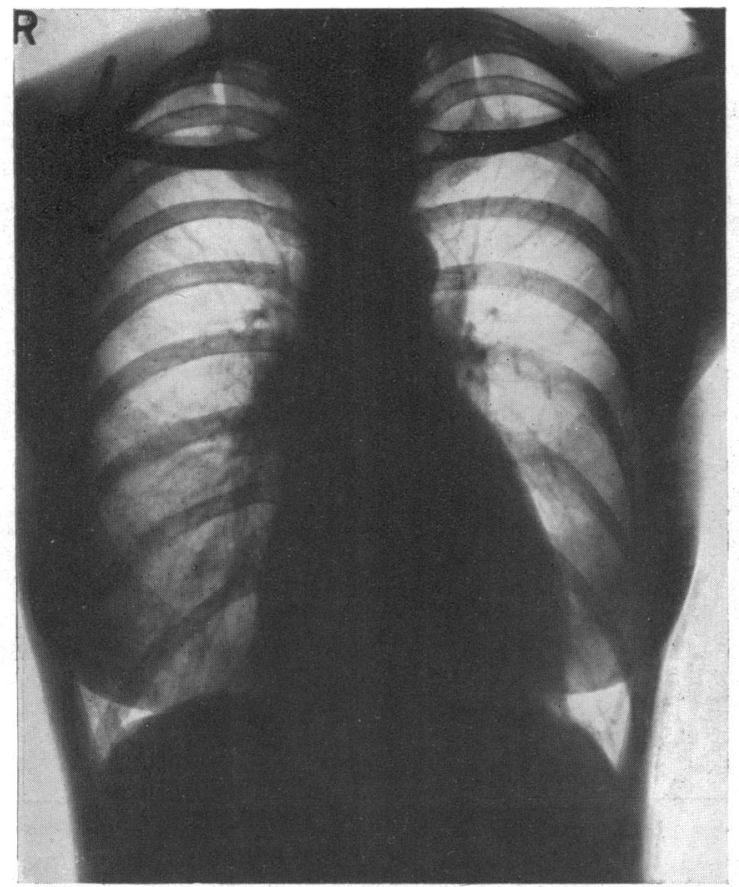

Fig. 3.-Woman, aged 51. Mitral stenosis, normal rhythm; radiograph shows some increase in left middle arc only. throughout; the mitral cusps were thick and opaque with rounded margins and the orifice easily admitted four fingers. The left auricle was greatly enlarged with a capacity of over $500 \mathrm{ml}$. (Fig. 13.) A fourth necropsy on a woman of 59 who died in congestive failure, shows a heart weighing $750 \mathrm{~g}$. with severe mitral stenosis and moderate aortic and tricuspid stenosis.

\section{Discussion}

The onset of auricular fibrillation appears to mark a turning point in the life history of patients who have suffered little or no handicap from mitral stenosis with normal rhythm up to middle or late life. Symptoms are rarely sufficient to make the patient seek advice till an arrhythmia develops, nearly always fibrillation, but occasionally it is auricular tachycardia that is responsible for the breakdown. Only three patients had normal rhythm when they first came under observation. Once fibrillation has become installed the patients' activities are more or less curtailed and their lives must thereafter be lived in a state varying from slight

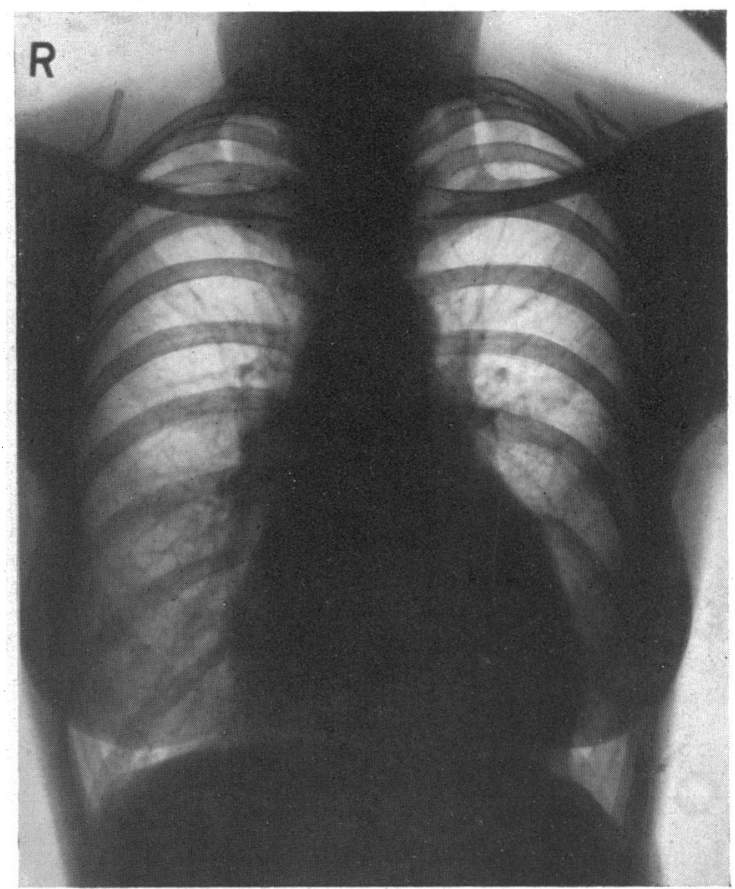

Fig. 4.- Same case as Fig. 3. Radiograph taken a few weeks later, after onset of auricular fibrillation, now shows greater prominence of left middle arc and some increase in left lower and right contours, although there were no clinical signs of venous congestion. 
to severe invalidism. At the first appearance of fibrillation with a rapid ventricle or of paroxysmal tachycardia, systemic congestion may occur but this is usually amenable to treatment after which there may be a long period of fair comfort. In some cases systemic congestion is delayed for years after the onset of fibrillation but when it does eventually occur it is resistant to treatment. Life may nevertheless be prolonged for years in a condition of advanced failure. The duration of symptoms that were more or less incapacitating averaged $4 \frac{1}{2}$ years for the whole series with extreme for a few weeks to 25 years. The commonest cause of death was systemic congestion with pulmonary infarction and cerebral vascular lesions as occasional contributory causes, but in two patients, one with severe hypertension, it was left ventricular failure. Two patients who died from left auricular thrombosis are of interest, in that neither had shown systemic congestion in spite of severe mitral stenosis.

The radiographic appearance of the heart in mitral stenosis of later life shows some differences from the typical picture in young subjects with this valve lesion; the heart is usually much enlarged and the aortic knob is not small; often it is prominent and shows calcification of its wall. Barium swallow sometimes shows a conspicuous aortic impression. Left auricular enlargement was revealed by the œsophagogram, yet in cases where the enlargement was great, as indicated by its extension to form part of the right cardiac border, œsophageal displacement in the first oblique position was only moderate. In two the œsophagus was displaced considerably to the left and backward. Displacement in this direction can be seen only by screening in the second oblique or face positions; it is very rare in mitral stenosis in young subjects.

Although a valve lesion or heart disease had been diagnosed in 8 of the patients when they were young, only 3 of the 38 cases described were referred with the diagnosis of mitral stenosis and it seems probable that many elderly patients with this valve lesion are not recognized as such. The mitral diastolic murmur often needs careful auscultation for its

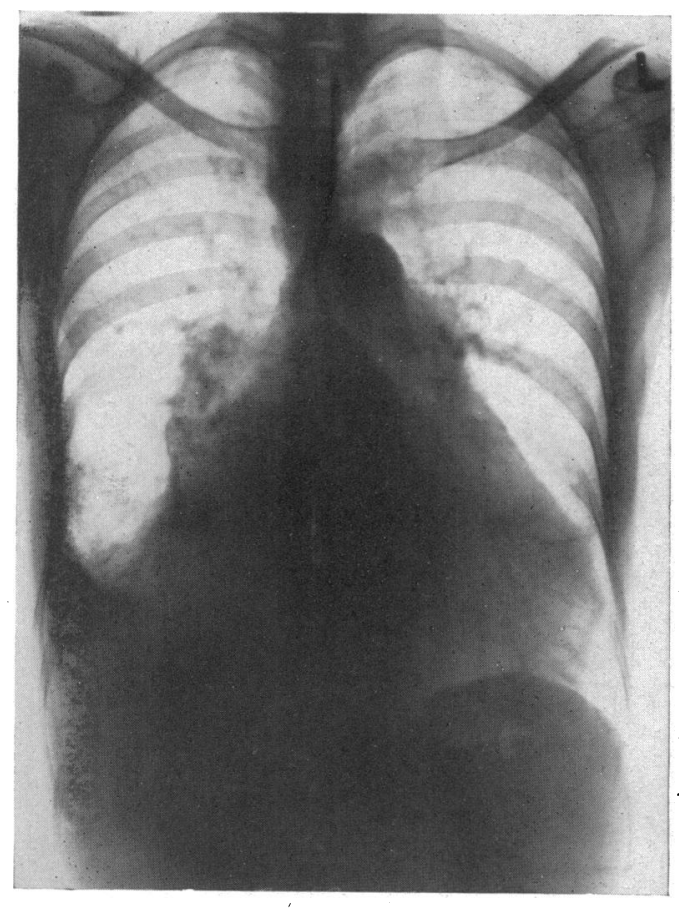

Fig. 5.-Woman, aged 58. Mitral stenosis, auricular fibrillation, hypertension $(260 / 110)$, congestive failure; working as domestic servant until a few days previously, Postero-anterior radiograph shows great cardiac enlargement, straight left border; œsophagus seen through heart shadow, is deviated to left. Right pleural effusion.

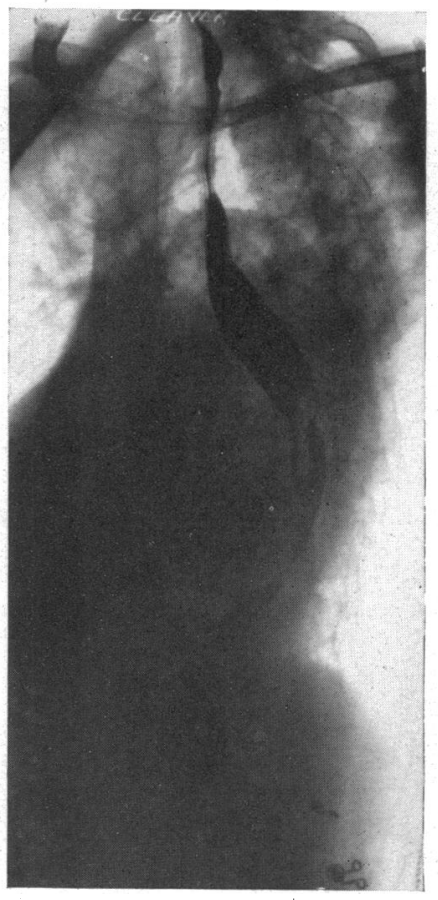

FIG. 6.-Same case as Fig. 5. Left (II) oblique view; leftauricular enlargement shown by displaced œsophagus.

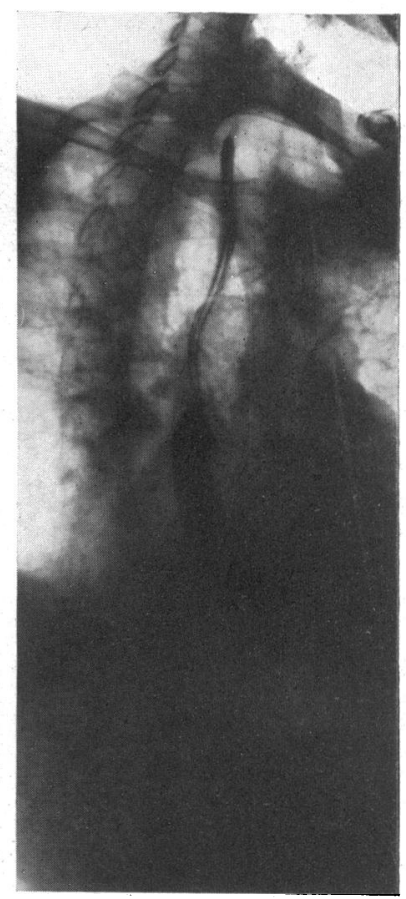

Fig. 7.-Same case as Fig. 5 and 6. Right (I) oblique view; œsophagus not displaced by left auricle but the shadow of the L.A. can be seen extending backward across the spine. Calcification of aortic arch. 
detection when auricular fibrillation is present and the site of audibility may be very localized. Moreover there is a general reluctance to diagnose rheumatic heart disease in the elderly, which makes it more unlikely that the characteristic signs will be found. Hence a diagnosis of arteriosclerosis or hypertension - which are also frequently present-is made. There is little reason to think that an atheromatous lesion with calcification was responsible for any of the present cases, and it is not established that such a lesion can produce mitral obstruction of clinical importance. In about 60 per cent there was a clear history of rheumatic fever or of a cardiac lesion having been found in early life. The absence or mildness of symptoms in the present group until late in life, is perhaps to be accounted for by a relatively slight myocardial injury; in a few perhaps by the first attack of rheumatic fever occurring at a relatively advanced age. It is not due merely to the slightness of the valvular stenosis, as indicated by extreme narrowing of the mitral valve in two patients who came to autopsy, neither of whom had ever had congestive failure.
White and Bland (1941) describe similar severe latent mitral stenosis in three patients aged 73 or more. It is evident that as with some other obstructions to the main vascular channels, such as severe aortic stenosis and aortic coarctation, an advanced lesion of this valve is compatible with good health over very long periods of time.

\section{SUMMARY}

Thirty-eight patients, aged 51 to 77 , with mitral stenosis (including one with pure mitral incompetence) are described. The valve lesion was believed to be rheumatic in all cases. Sixty per cent gave a clear history of rheumatic fever, or of a cardiac lesion having been discovered in early life. In a few cases the first known attack of rheumatic fever occurred in the fourth decade or later. Physical activity had been little, or not at all, restricted in the past and the appearance of symptoms calling for medical care coincided nearly always with the onset of auricular fibrillation, though occasionally with paroxysmal tachycardia. There was arterial hyper-

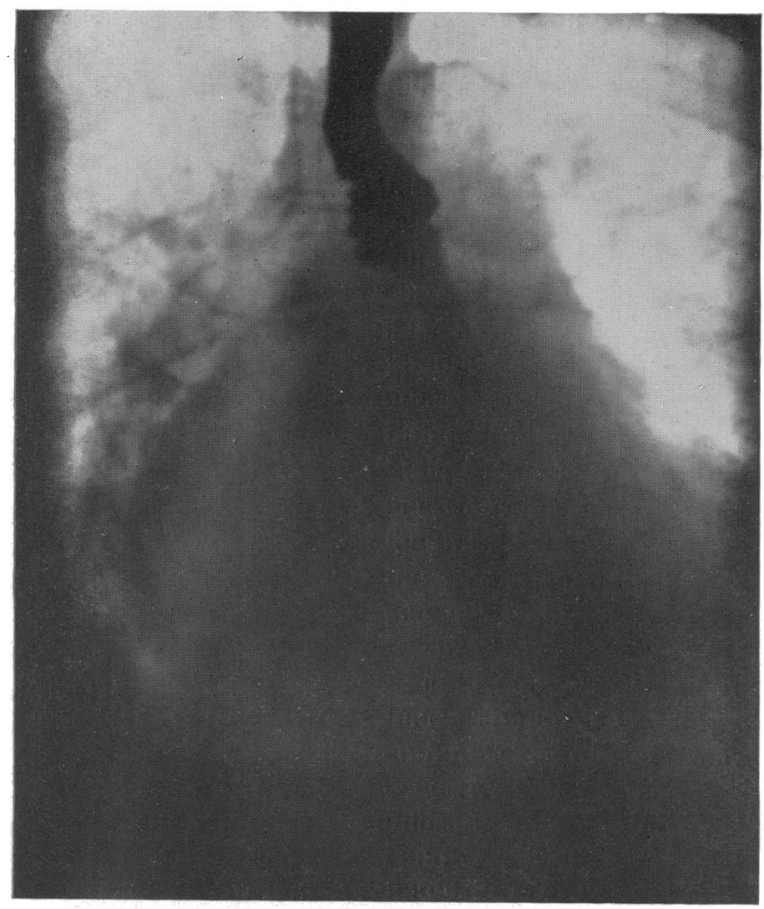

FIG. 8.-Woman, aged 66. Mitral stenosis, auricular fibrillation, hypertension (245/150) and congestive failure. Great general enlargement of the heart; very slight convexity of left middle arc; œsophagus pushed to left by large left auricle; deep aortic impression on œsophagus; calcification of aortic knob. 
tension in a high proportion of the patients. The $\mathrm{X}$-ray picture differs in several respects from that of younger subjects with mitral stenosis. Initial symptoms, occurrence of congestive failure and cause of death are discussed. It is suggested that mitral stenosis is not rare in patients over 50 years of age and that careful auscultation of elderly subjects with auricular fibrillation will reveal this valve lesion, where formerly it was unsuspected.

\section{REFERENCES}

Brenner, O. (1934). Birm. Med. Review, 9, 193.

Cabot, R. C. (1926). Facts on the Heart, Philadelphia, W. B. Saunders \& Co.

Cookson, H. (1930). Quart. J. Med., 23, 309.

Coombs, C. (1924). Rheumatic Heart Disease, Bristol, J. Wright.

Evans, W., and Benson, R. (1948). Brit. Heart J., $10,39$.

Gelfman, R. (1943). Ann. intern. Med., 19, 253.

Hedley, O. F. (1940). Pub. Health Reports, 55, 1707.
Karsner, T. H., and Koletsky, S. (1947). Calcific Disease of the Aortic Valve, London, J. P. Lippincott Co.

Levine, S. A., and Kauver, A. J. (1941-2). J. Mt. Sinai Hosp., 8, 754.

- (1945). Clinical Heart Disease, London, W. B. Saunders \& Co.

White, P. D., and Bland, E. F. (1941). J. Amer. med. Ass., 116, 2001.

Zeman, F. D. (1945). Amer. Heart J., 29, 661.

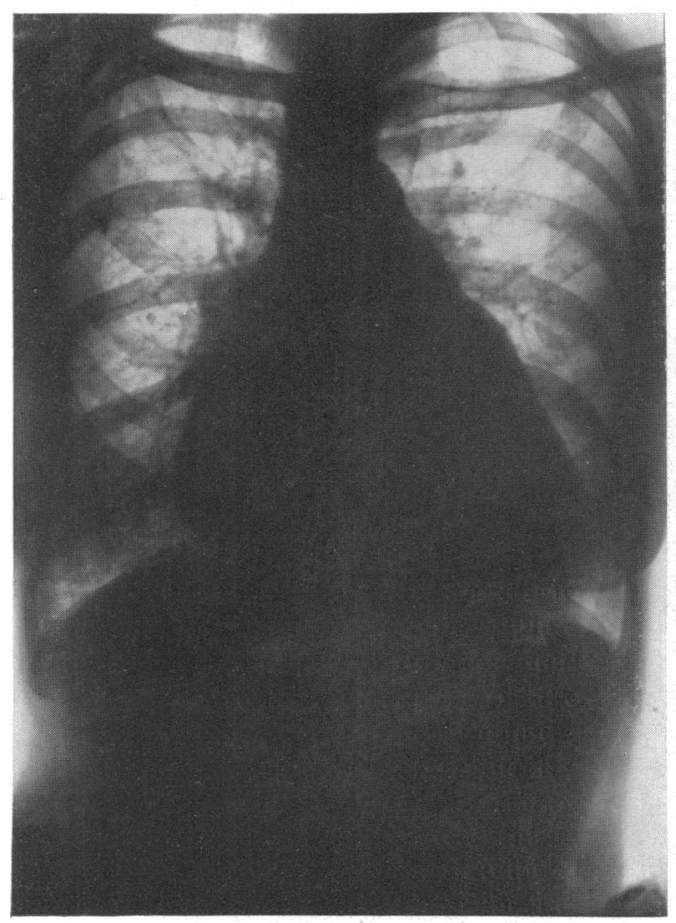

A

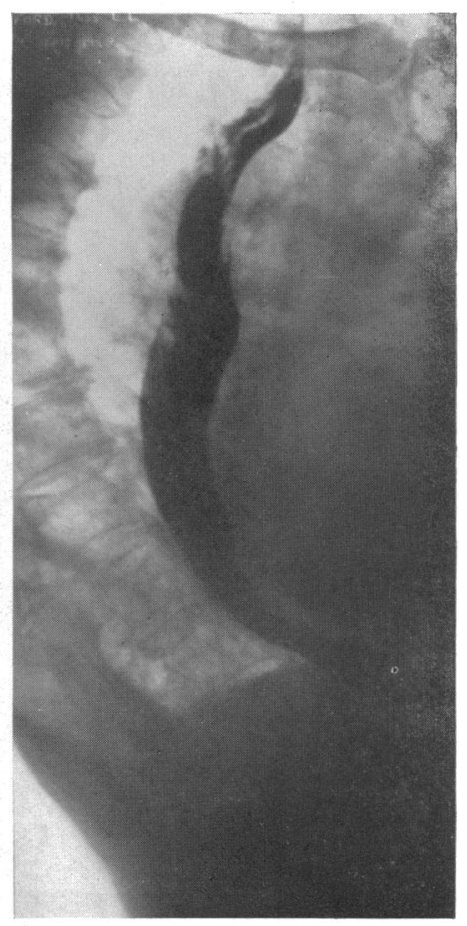

$\mathrm{B}$

FIG. 9.-Woman, aged 71. Mitral stenosis, slight aortic incompetence, auricular fibrillation; no signs of systemic congestion; B.P. 160/100. (A) Postero-anterior view shows considerable cardiac enlargement; small convexities on upper part of left profile. (B) Right (I) oblique view shows œsophageal displacement by left auricle. 


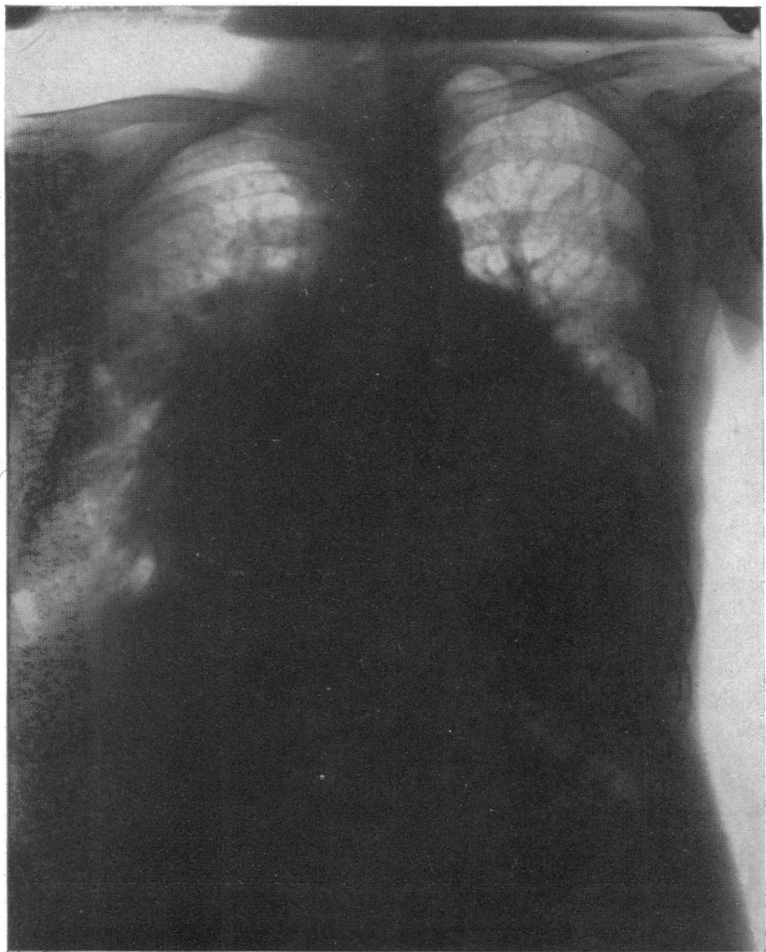

FIG. 10.-Woman, aged 77. Mitral stenosis, aortic incompetence, auricular fibrillation, congestive failure. Postero-anterior view shows very great cardiac enlargement of crinoline shape with a relatively narrow waist above formed by the vascular pedicle; left middle arc very prominent; pulmonary opacities suggesting hæmosiderosis.

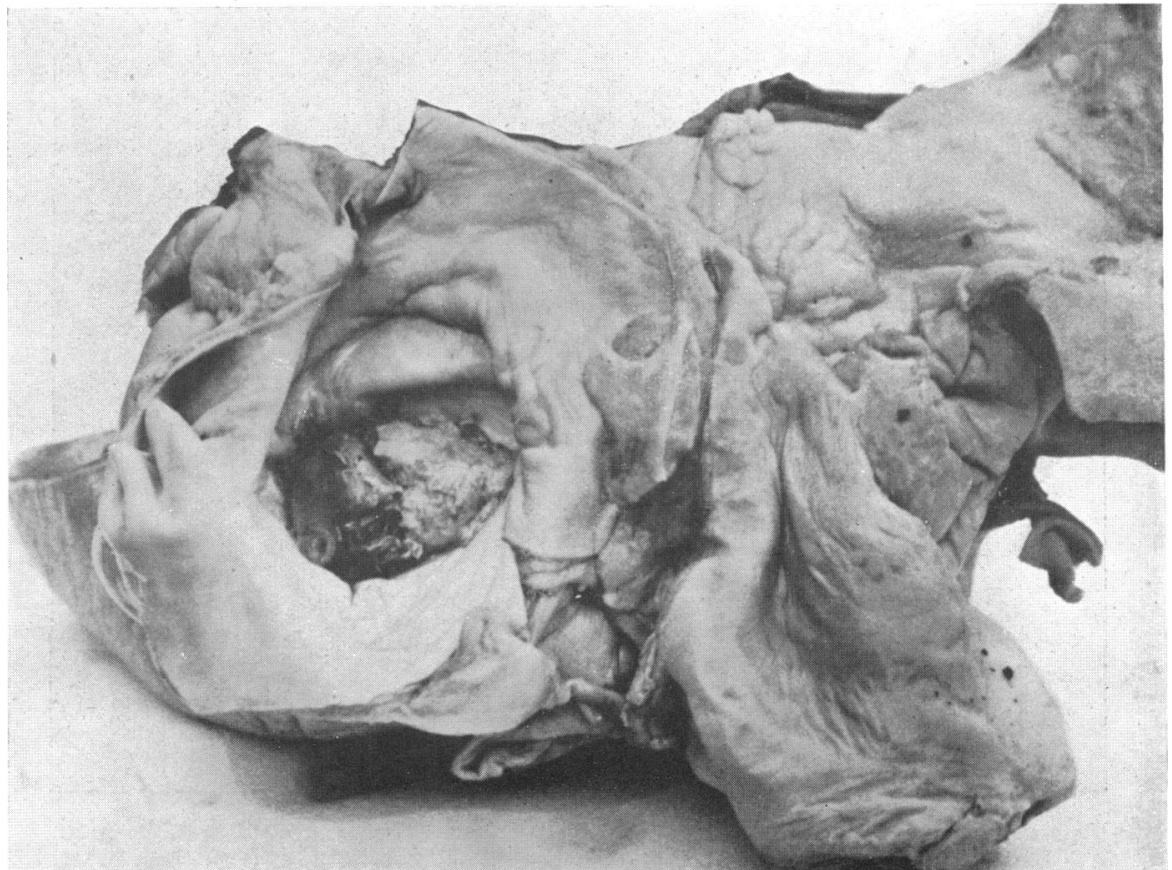

FIG. 11.-Heart from man aged 60. Mitral stenosis, auricular fibrillation; no systemic congestion; death from gangrene of the legs. Photograph shows opened left auricle to the left of the specimen; and a thrombus measuring $3 \mathrm{~cm} . \times 2 \mathrm{~cm}$. on the wall of the auricle which extends on to the aortic cusp of the mitral valve and further obstructs its orifice. Mitral opening just admitted tip of little finger. 


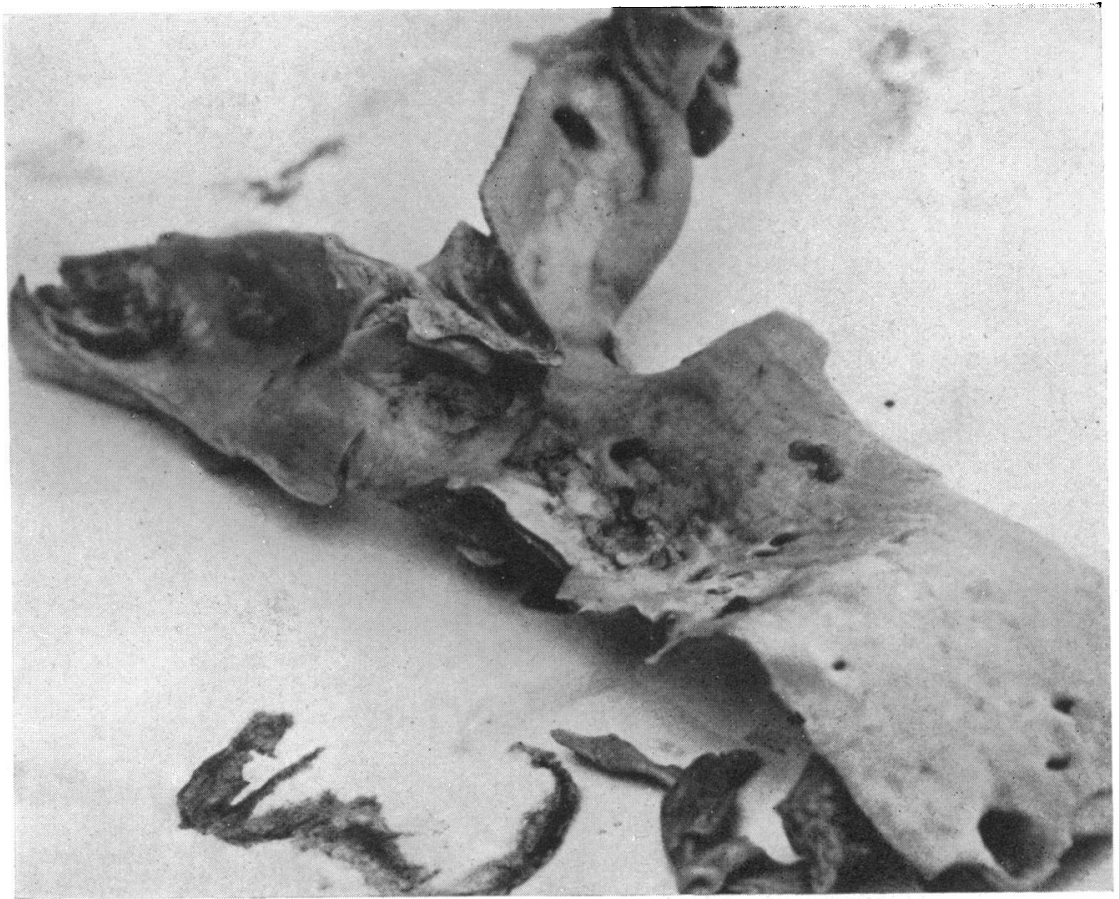

Fig. 12.-Abdominal aorta from same patient as Fig. 11. Shows perforated atheromatous ulcer just above the bifurcation.

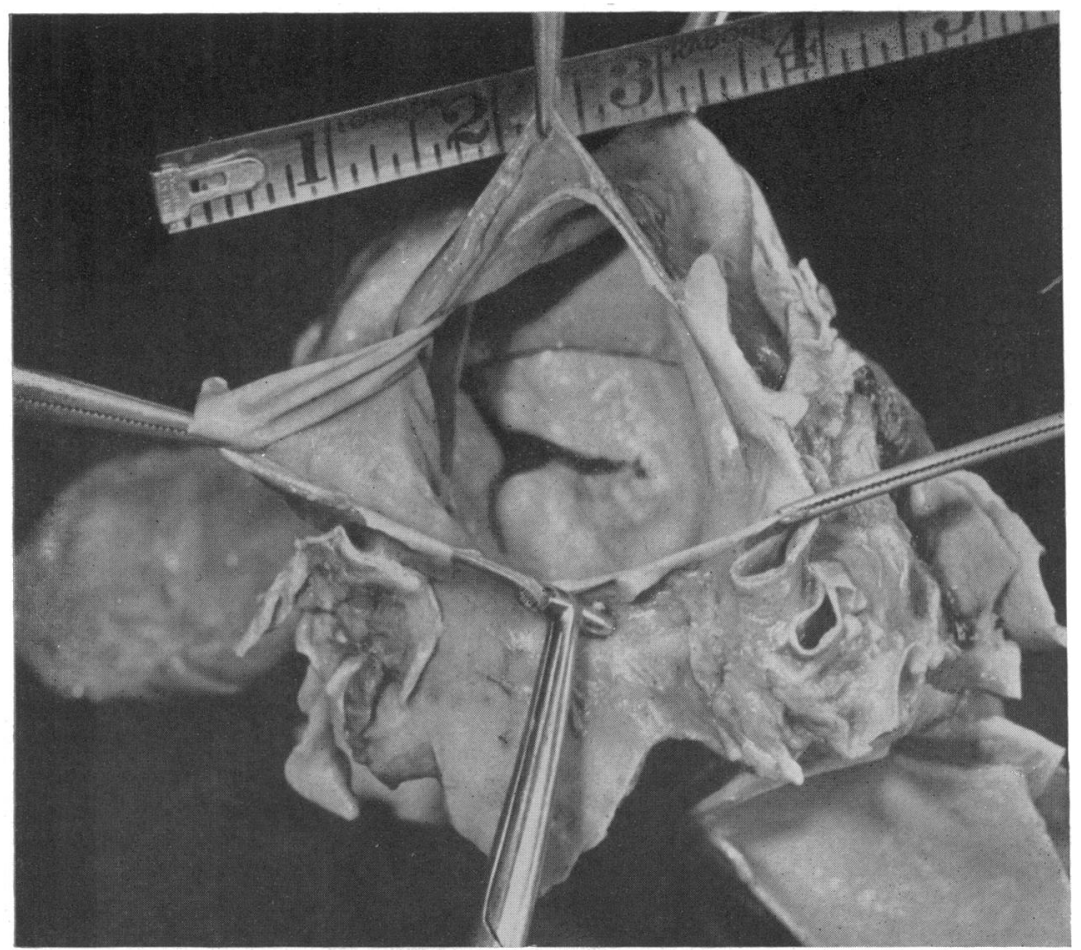

FIG. 13.- Heart from woman aged 62. History of rheumatic fever in childhood. Clinical diagnosis hypertension (215/115) auricular fibrillation, congestive failure. Necropsy showed adherent pericardium and as shown in photograph, large left auricle with a capacity of $500 \mathrm{ml}$; ; thickened opaque mitral cusps with rounded margins, the orifice admitting four fingers. This was regarded as rheumatic mitral incompetence without stenosis. 